\title{
Understanding the Status of Computer Education in the State of Uttarakhand: A Case Study of Roorkee
}

\author{
Udit Aggarwal \\ Aspirational District Fellow, Ministry of Home Affairs, Government of India \\ udit.a2605@gmail.com
}

\begin{abstract}
Across the globe, many spheres of our lives whether it is related to the day to day functioning at the personal level or administration of various governments are transformed with the advent of Information and Communication Technology (ICT). In the present century, indeed, the Information and Communication Technology's convergence has to also accelerate the evolution of diverse services in the contour of e-Initiatives or to be particular e-Governance.

Over almost three decades back with the modest commencement of e-Initiatives in various parts of the world, these engineering sciences have inarguably transformed some of the most rudimentary issues that at times trammeled communication and global outreach. In the state of Uttarakhand, many e-Initiatives have been launched to bring development to the state. Indeed, many efforts were taken to bring or to deploy e- Initiatives in the state, but there is a need to do a lot of work in terms of implementation and practical realization of the programs so that better services to the citizens of the state could be delivered.

This study would focus on a phased approach towards analyzing and realizing the impacts of e-initiatives taken by the state of Uttarakhand in the Education sector. This work would try to put forward an attempt to ascertain and explain the issues concerning e-initiatives taken in the sector of school education and would present a general review of the present model with a case study of city Roorkee. The computer literacy aspect among the school going children has also been taken up by analyzing their computer operating skills and knowledge. The study would reflect recommendations on the effective implementation of e-Initiatives in the sector of school education in the state so that a better education facility could be availed by the children.

Index Terms-Computer Education, Information Communication Technology in Schools, Computer and Learning Outcomes, Computer and Taboo, Government Schools v/s Private Schools, Computer Education in $21^{\text {st }}$ Century
\end{abstract}

\section{INTRODUCTION}

$\mathrm{T}$ HIS century belongs to science and technology and in this era computer education has become a very integral part of every kind of profession. Almost every domain of our lives can be experienced dominated by computer programs. But technology has struggled to explore its way into the classrooms. It is equally imperative along with bettering the ways students are taught that students learn how to use the computers to develop their skills and get ready for careers in a world where computers have become as plebeians as the pen, pencil and, paper. It is often said that students are future leaders for any country. Children who are in school presently are future doctors, engineers, entrepreneurs, etc. and hence it becomes very important for the development of education that students must be taught about the computer, internet, and its benefits.

Information and Communication Technology (ICT) could prove to be the tool to bridge the digital divide amongst students of various socio-economic backgrounds and beyond geographical barriers. To bring social change and national development, it is universally acknowledged that ICT could be an important catalyst for the same. In this context, the Indian government has announced 20102020 as the innovation decade and for innovation, skills of reasoning and critical thinking are essential. Such skills need to be inculcated amongst students from the very beginning of the school level i.e. from the primary level and to nurture these skills classrooms need to be integrated with ICT.

UNESCO said that to achieve millennium development goals, education is important and without it, MDGs cannot be aimed at. Hence it becomes necessary to integrate ICT with education so that more people could develop and witness the growth, more people could acquire knowledge and learn more equal and just society, more mothers would be healthier and more children would survive and live, more people would think of future and more of them could work together.

The government of India had initiated ICT integration into selected primary, upper primary, and secondary schools aiming to expose children to the computer education system.

The main objectives of ICT in school education are:

- To develop the skills and scientific and technological temper among students of government schools.

- To reduce the span of the digital divide between urban and rural students. 
- To make students and teachers computer literate and aware.

- To develop an environment where the learning and teaching process would be more interesting and effective.

- To provide training to the teachers and educators on computer syllabi, advance information, and communication technologies.

- To inculcate ability and confidence among students to use computers in the future.

Brief about Uttarakhand and ICT plan: State government realized that the aim of education in the running Century is being redefined. It is to form a better world through understanding and growth of human traits and not only for employment generation. Undoubtedly information and communication technology has revolutionized the world of learning and in present times it is very imperative to integrate IT with education in order to have the advantage of edge education. What has been stated by the state government as the objective of integrating ICT with schooling and education plan is to empower students with skills, knowledge, and understanding, to motivate students to become autonomous learners and encouraging elearning and to make education in schools relevant to present nature of workplaces. Thrust has been put on quality learning where the traditional rote learning method is demotivated, curriculum to be made enriched to go beyond textbooks, and facilitating the student to 'Learn to Learn' and 'How to Learn'.

Other than students, this plan is made to be used as an instrument for teachers' professional development. It is not true to say that a computer can replace teachers but enables them to transact teaching effectively. The State government's aim under this plan is to computerize all the schools under the 'Aarohi' program by installing 5 to 6 computers in each school.

The present status of computer coverage in schools is as follows:

\begin{tabular}{|l|l|l|}
\hline District & \multicolumn{1}{|c|}{$\begin{array}{c}\text { Computerised } \\
\text { Schools }\end{array}$} & No. of Computers \\
\hline Almora & 205 & 982 \\
\hline Bageshwar & 71 & 362 \\
\hline Pithoragarh & 142 & 685 \\
\hline Champawat & 61 & 202 \\
\hline Nainital & 156 & 833 \\
\hline $\begin{array}{l}\text { Udham } \\
\text { singh nagar }\end{array}$ & 91 & 664 \\
\hline Dehradun & 149 & 838 \\
\hline Tehri & 192 & 989 \\
\hline Chamoli & 133 & 729 \\
\hline
\end{tabular}

\begin{tabular}{|l|l|l|}
\hline District & \multicolumn{1}{|c|}{$\begin{array}{c}\text { Computerised } \\
\text { Schools }\end{array}$} & No. of Computers \\
\hline & & 1319 \\
\hline Pauri & 288 & 435 \\
\hline Rudraprayag & 85 & 429 \\
\hline Uttarkashi & 86 & 342 \\
\hline Haridwar & 50 & $\mathbf{8 8 9 9}$ \\
\hline Total & $\mathbf{1 7 0 9}$ & \\
\hline
\end{tabular}

(As per state's official website)

Simultaneously with the assistance of Microsoft and Intel, efforts are made to train the teachers. There are 17,170 teachers are working in secondary schools.

\section{REVIEW OF Literature}

India draws a bead on to egress as the information and technology leader among the societies which are knowledge-based; it does so with the addition of children education as one of the basal concern. With the enforcement and enactment of the Right of Children to Free and Compulsory Education Act 2009, the government of India has corroborated its allegiance to ensuring universal elementary education for all. The Right to Education Act also includes the provisions for preparing Indian Children with 21 st-century skills, to be specific, digital skills, and computer operating skills. However, India emerged as a hub for IT services, the economy shifted from agricultural to service economy after accepting the neo-liberal reforms of the 1990s, the status of computer education among school-going children, particularly those who are getting an education in government-run schools, is not up to the mark and it has various reasons responsible.

There is a huge number of literature available regarding ICT applications but lesser comparatively regarding the impact of ICT on the learning and achievements of the children. Most of the literature in this area of study is reported from other countries specifically the western developed world. There is an attempt in this chapter to present a summary of related literature under these headings:

1. Computers' Use at School level: Understanding the Effects.

2. Teachers and the use of ICT

3. The Education system of India: In the context of Computer Education

\section{A. Computers' Use at School level: Understanding the Effects}

Wighting M J (2006) used a mixed-method design among high school students to ascertain how far the com- 
puters' use in the school classes affect the sense of learning in the community. The main objectives of his study are to determine the technological use in classrooms affect students' sense of learning in a community of the classroom and also to study how do the students delineate the classroom community and its necessity for their learning. After the analysis, it was reasoned out that:

1. Participants have a sense of classroom community and some of them were mindful of the feeling community and might be benefitted from the same.

2. Many participants are of the view that the community helped them in the learning process and important for them.

3. When concerning the sense of community and its necessity in learning, students identified the three major factors which include the use of computer and technology, sense of community, and the element of learner control.

4. Students uttered that they believed they had control over their learning with the computer to a greater extent when compared to learning through the books.

5. Students well thought of that they were learning conjointly in a community and building on information that they incurred either as a class or individually.

The limitation of the study is that the author discussed the students' community but the factors which influence the community were not taken into account.

Sutton and Kafai Y B (1999) have reviewed the use of the computer at school and the internet at the home of elementary school students. The outcome of the study indicated that most of the students' use of computers dedicated to games which followed by many other software activities. On the question of connecting the use of the computer at home and school, the suggestions of parents focused on ways in which information about the students may be availed from the school and support via exchanges with teachers.

The limitation to the above study is that the discussion over infrastructure which would be required at home and school is completely missed out. It only talks about the role of parents and potential directions in academic home computing.

\section{B. Teachers and the Use of ICT}

To identify the factors which can be proved most effective in encouraging and enabling teachers to use ICT, Scrim Shaw Peter (2004) reviewed the literature existing on enabling teachers to use ICT. There was an online survey conducted, visitors of the Becta Research website invited to list out the factors which they consider enabled them to integrate ICT in their teaching. The outcomes of the study suggested that the majority of teachers prefer to use a different version of the teacher-centered model. It is requisite for teachers to make changes in the ways they teach and there they have to make maximum use of ICT. Also, the personal characteristics of teachers may shape the extent they take up an innovation. There are different levels of teacher use of computers varying with their relationship with existing curricula. Some of them use ICT as a supplement to the curriculum; some use it as reinforcement on the advancement of the curriculum. Because of this, the training provisions have to be secernate to cope with the needs of teachers to ensure widespread use of ICT (teacher-level factors). There also exist school-level factors that can subdue its use and hence both school level and teacher-level factors need to be addressed.

Steve Kennewell (2004) has analyzed a range of case studies in order to précis the general principles to help new teachers to realize something of composite relationships involved in ICT's effective use in teaching and learning. Rather than imitating their mentors, the new teachers or trainee teachers should be able to plan for themselves using this understanding. These general principles for the new teachers furnish a basis for evaluating their practice and hash out how to improve. 'Thinking together' is one of the principles, where teaching student how to talk together, discuss together is a way of promoting effective thinking. 'Literacy and ICT' is another important principle where an association of computer integrated activities and collaborative learning could endorse literacy development. If to bring the transition from oracy to literacy then the computer has a crucial role to play in. But the author's study came up with a limitation as the author discussed the relationship between the oracy to literacy among students but not successful in portraying the findings of its initiatives.

\section{Education System of India: In Context of Computer Education}

The study was to ascertain the defiance Indian educational system facing in achieving universal access to quality and relevant education. Solutions to such challenges are related to the use of ICT and it becomes an area of interest for people around the world. The ministry of human resource and development initiated a program for universal access to develop the quality of education in secondary schools knows as RMSA (Rashtriya Madhyamik Shiksha Abhiyan) with the use of ICT having as the objective of transforming learning and teaching via ICT. However, in rural areas, there is no sufficient number of teachers who are competent in the use of computers, and even very less exposure to computers resulted in merely keeping computers inside the classrooms. Only when it can be said that beginning of the use of computers has started actually once the teachers, school staffs and students get more acquainted using computers. Only through the ICT literacy courses this kind of comfort can be 
achieved otherwise deploying computers directly into the classrooms would only be an "expensive deployment model".

In 2005, UNESCO and MHRD conducted a study to analyze the usage of ICT in one thousand schools of India to evaluate and monitor the use and outcomes of ICT to realize the benchmarks for programs and policy improvements. 1000 schools which surveyed include 500 from Gujarat and 500 from Karnataka. Out of these 1000 schools, 398 were private schools and 602 were government schools, out of these 513 secondary schools and 497 primary schools. Major findings of the study are:

1. The ICT use was very limited as the schools having ICT department was very limited, resource allocation in terms of funds was very limited, very less number of ICT trained teachers and limited per capita availability of hardware, etc.

2. There were less than 6 computers per school and one computer over 72 students on average.

To review the use of technology in the context of Indian education, Sanjay Gupta, Suresh Garg, and Jyotsna Dixit (2011) conducted a study. With the beginning of the 21 st century, we all realized that knowledge is the one major thing going to affect human endeavors in all spheres of life. In the 1970s and 80s, the material available on the web has certain limitations as it did not have appropriate instructional designs and also failed to provide an interesting learning atmosphere. In 1995, computers were equipped with CD-ROM drive which can save vast information in it per se audio, video, and image formats. But in 1996, there was a revolutionary development that happened when computer learning came with the Internet and the Internet proved to be the most efficient learning tool as it offers a global unbounded platform for information and communication. In the fact, the internet hasn't changed the expertise of learners and teachers though helped them to change their mode of production and skills.

The role of technology in India as a catalyst for teaching and learning is reviewed by Vijay Kumar R (2011) in his study. The fact to be acknowledged is that in today's teaching and learning process ICT has become a very integral part of it. If the technology is used effectively then it can regenerate the enthusiasm of teachers as they can learn new skills and also can prompt students to make classes more interesting and dynamic. Withal a teacher cannot be replaced by technology but can be used as an appurtenance tool in the entire learning process.

To ascertain the impact of ICT in classroom instruction, Anandan and Gopal (2011) conducted a study. There is a direct relationship between quality of education and quality of teachers; to a great extent, those teachers who use innovations in their teaching pedagogies through integrating technologies give the best to the students. Undoubtedly technology is a potent tool for solving prob- lems, critical thinking, and conceptual development and if used effectively then it could help the students to make the learning process easier. To make students achieve a high level of competency and competitiveness, teachers need to integrate technology in the field of education. Hence, a teacher can also be called a "Teaching Technician".

\section{PROPOSED STUdY}

To analyze the impact of ICT policy in the field of education which is initiated almost a decade back in the state of Uttarakhand. This study is significant in a way to realize that actually where are we heading in terms of policy implementation and to find out its effectiveness. This study would look for the three components of ICT plan i.e. infrastructure, students' computer literacy and teachers' preparedness. It will analyze the extent of ICT integration among schools happened, the availability of infrastructure, accessibility to ICT tools for students and teachers, also to ascertain the kind of behavioral changes occurred in students and teachers in this regard of integrating education with ICT.

\section{A. Research Questions}

1. What is the impact of ICT integrated education on secondary school students?

2. What is the attitude and acceptance level among teachers towards ICT integrated education?

\section{B. Objectives}

1. Ascertain the impacts of e-learning and computers on students' learning.

2. Ascertain the effect of computer literacy among students on their academic achievements.

3. Ascertain the extent of availability of resources and frequency and kind of uses.

4. To determine the effectiveness of the curriculum in computer education and what steps efforts are been made by teachers to promote computer education among students.

\section{Research Methodology}

The design of the research methodology was qualitative. We have used qualitative methodology because, in this study, the examining of the ICT system in education shall be done per se its weaknesses and strengths, an investigation will be done about its current positioning, will try to understand the perception of teachers and students about the respective topic, also to understand the feelings, values that underlie and influence behaviors. For this purpose, the case study approach is used and 45 students and 20 teachers selected as respondents. In order to collect the perceptions of the stakeholders, personal interviews are 
planned to be conducted using semi-structured and openended questionnaires.

For this research, the Roorkee block is selected for the case study. Roorkee block in total has 379 schools, including 107 primary schools, 26 upper primary schools, 7 government higher secondary schools, and 7 government inter colleges.

For this study, only government higher secondary schools and government inter colleges were taken into account. 45 students selected as respondents across 8 government higher secondary schools and governments inter colleges. Students belong to class IX to XII were selected as the respondents. The average age group they belong to is 15-20 years. Gender participation was in harmony and homogeneity. The average social category of the students is quite heterogeneous, as $40-50 \%$ of the students in every school belong to the SC category, $30-35 \%$ of them belong to either $\mathrm{OBC}$ or Minorities and the rest is other castes.

The 20 teachers were selected as respondents among 8 schools and are from various backgrounds such as Science, Mathematics and Languages, etc. The average age group they belong to is 33-56 years. Most of them are highly educated and completed their masters in their respective subjects along with other required training courses required to be a teacher in governments' schools. Interestingly, most of the teachers who are respondents belong to open categories or in other words, upper caste. However, this was not asked to them directly but analyzed with the surnames they informed while interviewing.

To know the situation of resource allocation from the government, a visit was done to District Education Head Office, located in Roshnabad, Haridwar. There happened one to one interactions with the officials to know and understand how execution is going on for integrating ICT with education. However things and evidence cannot be shared on record, but personal interviews provided substantial insights for this study.

To know the perceptions and understandings of those parents who send their wards in these government schools, telephonic conversation, and personal meetings were conducted. Most of them belong to economically and socially weaker sections who are largely indulged in daily wage-earning occupations or small businesses such as provision stores, knitting, etc. The education status of those parents was significantly low; hardly anyone of them achieved a high school education.

Data were collected by personally contacting the respondents, generally Focused Group Discussions (FGDs) for students, and one to one interview with the teachers either in person or on a phone call. All the respondents are residents of Roorkee block either the urban area or rural. The data were collected in the month of December 2018.

\section{ANALYSIS \& INTERPRETATION}

\section{A. Effectiveness of ICT on Education-Perception of Students}

1) Access

Access to computers, the internet, and other equipment is imperative for the students as it will directly and definitely affect the abilities of students and also it will ensure the development of technological knowledge to the students. The extent to which students have access to ICT decides their knowledge and skills.

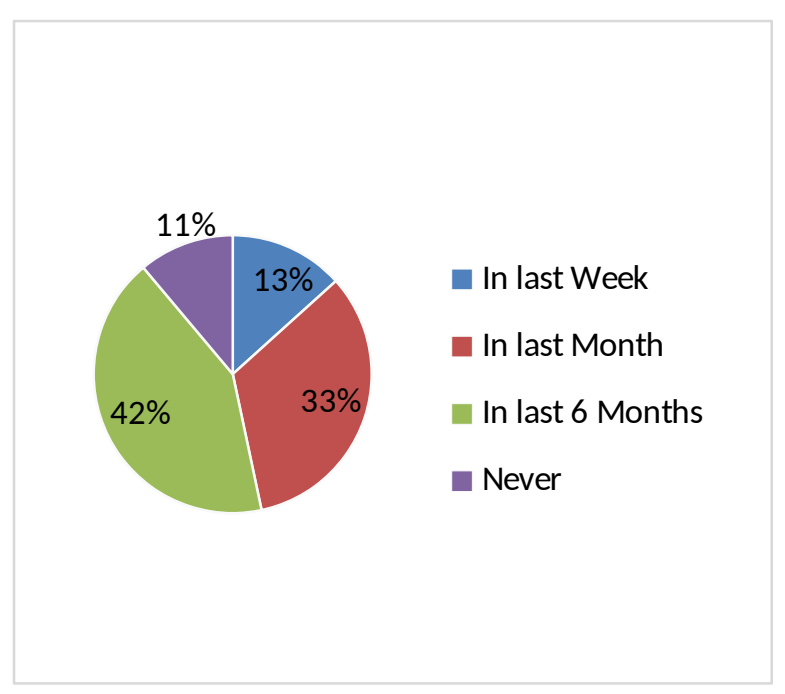

Fig.1: Use of Computer Outside School

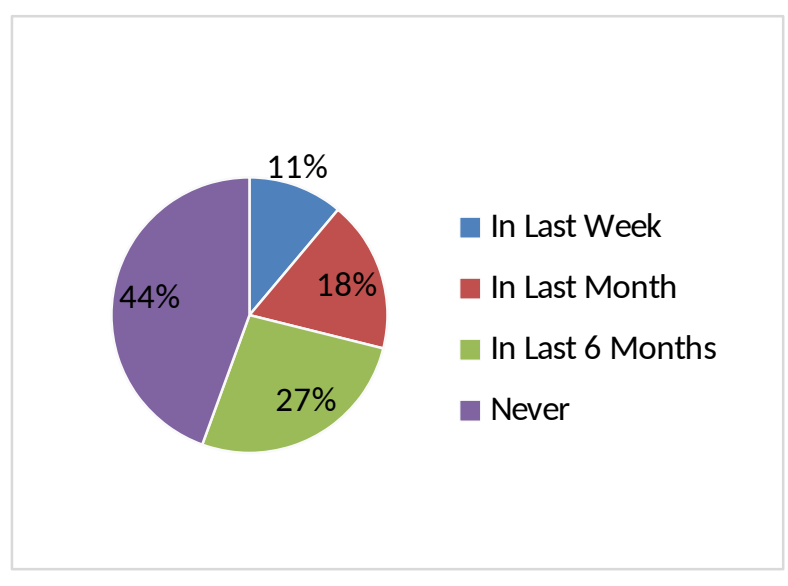

Fig. 2: Use of Computer in School

While analyzing the effectiveness of ICT in the case of Roorkee, access to the ICT emerged out to be a major limitation. It cannot be ignored that access to computers is dependent on the economic statuses which reflected in the responses where the majority of the students were never or used computers before 6 months outside of school. Those students who remained untouched from ICT in schools and even not having access to computers outside 
of the school are on the verge of a technologically illiterate situation. Owing to the absence of touch with this technology, computers remain an alien thing to the students.

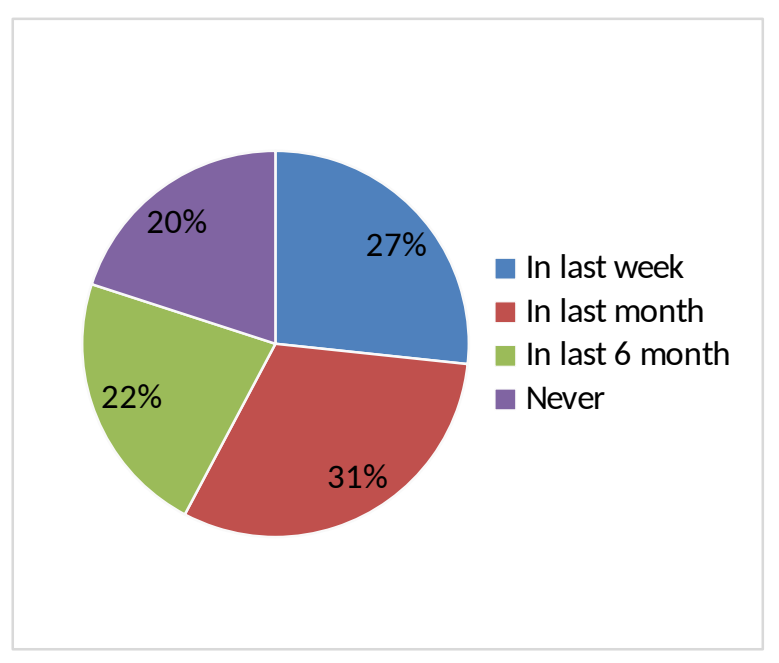

Fig. 3: Use of Internet

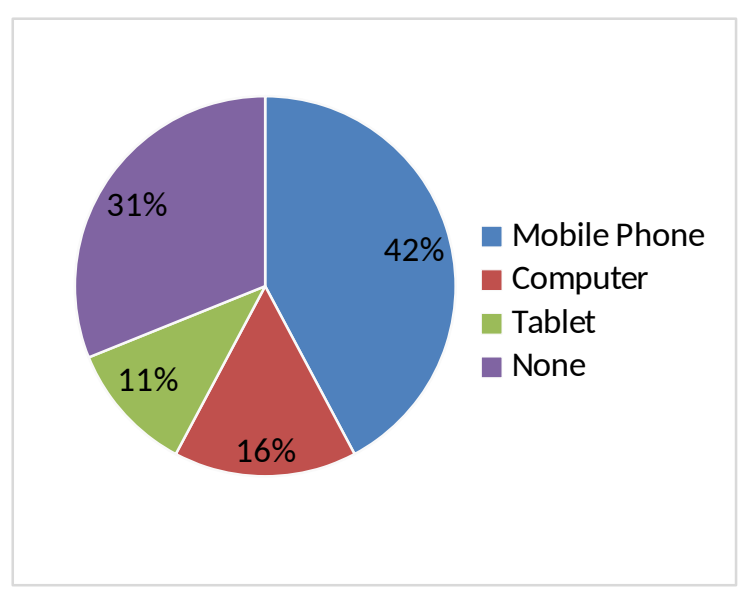

Fig. 4: Device used

One thing needs to be noted that it's not the case every student who has used the internet has his/her own device rather most of them have used it either on their parent's or friends' devices. The other shocking outcome from the fieldwork is that none of the students has ever accessed the internet on their schools' computer. Though schools have internet connection on a few systems, this is mostly for the use of clerical work or office use. Therefore, the students are not getting any benefit out of it. Again the usage of computers for this purpose too remains quite low and the undisputed reason came out is the lack of awareness of the functioning of computers. Most of them were of the view that they don't know how to operate a computer, and as they were never been in contact with com- puter usage, machines remain quite an alien thing to them and hence hesitated to use it. Because of this gap, they instilled with the fear that if they use a computer then something would definitely go wrong with the machine which they won't be able to correct.

On the lighter note, when asked how they have access to mobile phones and not to computers, mobile phones are very cheap in comparison with computers and necessity nowadays they replied. The average cost of their mobile phones varied from five thousand to 10 thousand and most of them informed that, since Jio introduced cheaper internet plans they were able to use the internet which is not the case earlier. They used to do recharge for internet packs in partnership with their friends. But this is an entirely different topic to do research on.

It is also important to ascertain how the students who have access to the computers and internet use it.

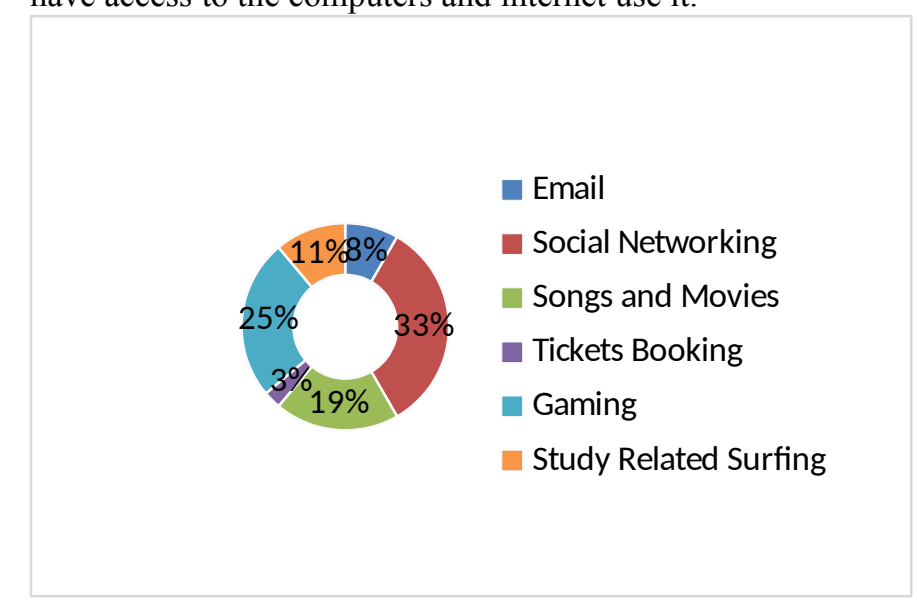

Fig. 5: Activities over Internet

Apparently, those students who have access to the internet and mobile phones use it for social networking sites, specifically Whatsapp and Facebook. But when asked about the features of Facebook, they came out as very less informed and also struggles with the language barrier in operating Facebook. Moreover, for them, predominantly Facebook is all about sharing pictures and videos. Here most important point to be noted is that none of them are aware of internet safety features regarding how to be safe while using the internet and social networking sites as they generally share their passwords among their friends and often ask their friends to do activities on behalf of them. They are even less informed about how to distinguish between fake news and in a way became prone to false news propaganda. What more problematic here is that usage of the internet and mobile devices remained very low when it comes to studying related surfing including using a dictionary, finding topics and lectures, etc. The very reason behind this could be the ineffective implementation of curriculum as it fails to push students to use the least available facilities construc- 
tively and hence in absence of proper guidance their usage is largely limited to online movies and songs, gaming, and social networking sites. Out of all the respondents, only two said that they have used Email, and the rest of them never used this, more shockingly they don't even have mail IDs. This is valid to say that students are less aware of the productive usage of ICT.

2) Ability

A decade back, most of the private schools witnessed the ICT revolution with the introduction of SMART classes but few government schools received this development and those schools that have received it are not in the condition to use it properly. This is again an example of how ineffectively the curriculum is followed despite having guidelines.

Surprisingly none of the computer labs has an internet connection to them as informed by the students. Then what they do while visiting the computer labs was the next question. Regarding this, they opined, "We used to go and sit in groups, there was an instructor who comes to each group one by one, explain the names of the parts and their functioning and names of software installed in it". There was a school whose principal informed that they were provided with ten computers by the government a decade back, but due to lack of infrastructure machines were ruined due to rains and now they are left with nil working machines.

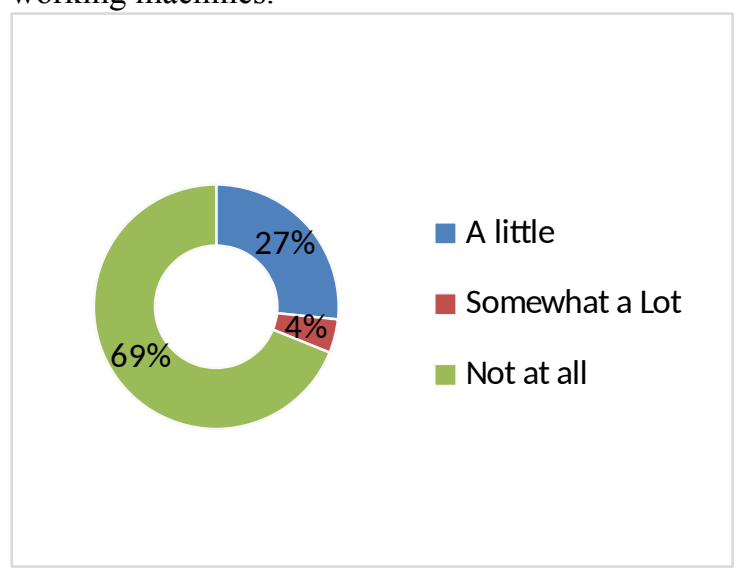

Fig. 6: Producing text using MS-Word

The ability of the students to produce a word file or PowerPoint file is highly limited. Most of the students have never used these features on their will and never asked to do so by their instructors as well, moreover cannot even identify the icons to such applications. Those who informed that they can perform a little on MS Word also said that they are not proficient in the English language and hence cannot produce a file on their own but can copy from the book. One more thing to be noted is that, none of them are with typing skills, hence typing speed remains very slow.

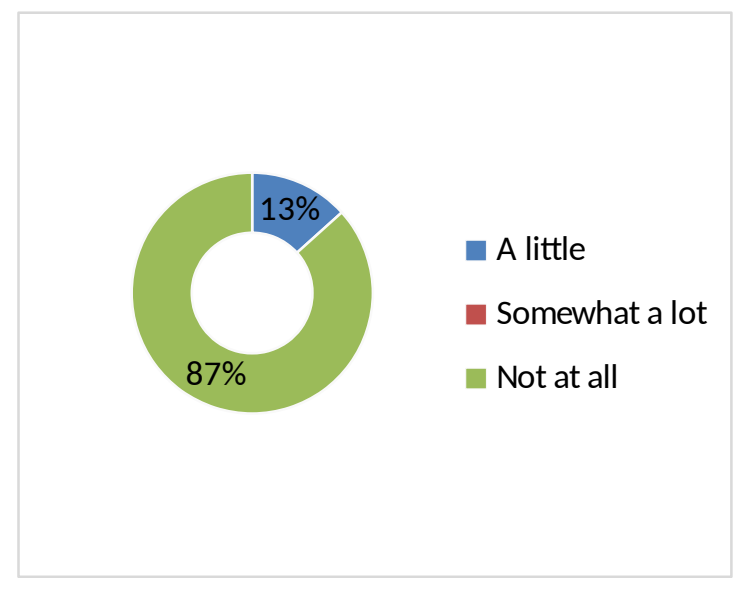

Fig. 7: PowerPoint Presentations

There were few responses in the case of MS Word who know somewhat a lot about the functioning, but none of them is completely proficient in performing actions in PowerPoint. Students responded in a way as if they are hearing about it for the first time. Not so surprisingly most of the respondents said that they are completely unaware of PowerPoint functioning. Those who have said that they know a little about PowerPoint do not know how to make multimedia PowerPoint presentations. Even they never made any presentation for the classrooms.

3) Attitude

When asked about the necessity of computer education to improve learning, most of the students strongly agreed with its necessity, and none of them show their disagreement with this. One could undoubtedly argue from their responses that they want to have access to computer education and ICT so that they can make themselves compatible with the advanced world. When asked to them about the role of computer education in getting a good job, most of them agreed but a few among them have also said that "No, computer education is not necessary to get a job". In their view, computer education is required for a specific kind of job and not for every kind of job. This shows how being unaware or untouched by the technological advancements in education caused them to be completely unknown from the changing job dynamics. Few of them wanted to be a teacher, few of them wanted to be bank personnel, few wanted to have a job in a private firm but not knowing how knowledge of computer could help them to pursue their dream careers.

Owing to very less exposure to cyber cafes and computer machines, the computers were seen as taboo in few societies and families and it was evident from the behavior and responses of a few students. When students were asked informally about using cyber cafés and going there to use computer machines, then they became shy and smiled. Few girl students responded with a shyness that 
"Cyber café is not a good place to go". They have a taboo associated that cybercafes are those places where people go to watch porn and hence they never visited neither think of going. The same is the case with a few boy students who started looking at each other's faces and smiling when asked the same question. Also few of them have admitted that they used to go to cyber café with their friends to play games and not that frequently.

Presently, there is a high gap between the students who are in state-run schools and who are in privately run schools in terms of having technologically supported education. Respondents to this study have displayed theoretical knowledge about computer education which is again highly limited to the basic definitions of the parts of the computer as one respondent said when asked about CPU, "CPU is the brain of the computer". Computer education remains a subject that has the lowest participation from the students owing to various reasons discussed above. Moreover, there is a lack of faculty to teach students and there is no dedicated teacher for computer education only. There is a need of taking corrective and efficient measures to improve the current situation otherwise it would surely widen this divide.

\section{B. Effectiveness of ICT on Education-Perception of Teachers}

\section{1) Access}

The major factor which limits the teachers from using ICT in teaching and learning per se education is access to technology. The responses in general painted a dark picture related to the reality of technology access in schools.

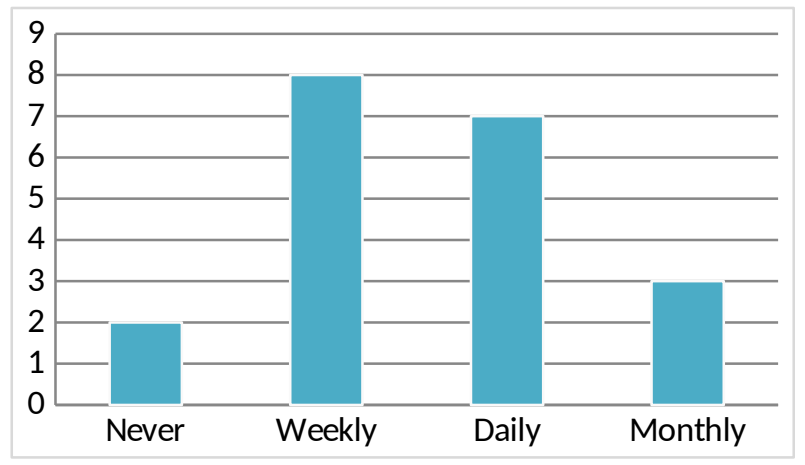

Fig. 8: Use of computer for activities other than school work

The responses clearly show that teachers in their personal space have better access to ICT tools such as computers as data clearly shows that most of the teachers use them either daily or weekly at least. Here, other activities included shopping, socializing, entertainment, etc. and for one or another purpose, they use a computer either weekly or daily. The age bracket of the teachers came out to be a striking feature in it, as those who are in the age bracket 28-45 are the most frequent users. However, in the case of teachers, the use of ICT in their domain is highly accessible but the situation is completely reverse in the work domain i.e. in schools. Teachers have very limited access to ICT in schools which limits their capabilities of introducing technologies in their teaching pedagogy and instruction methods owing to lack of infrastructure. Though this is a reality that every school is digitized its ambit remains very limited. Digitization of the schools is limited to the clerical work solely where the data related to students; their performances and attendances etc. need to be updated on the government portal. Surprisingly not firm actions and efficient policies were made to ensure access to ICT for teachers as well as for students which will be discussed later.

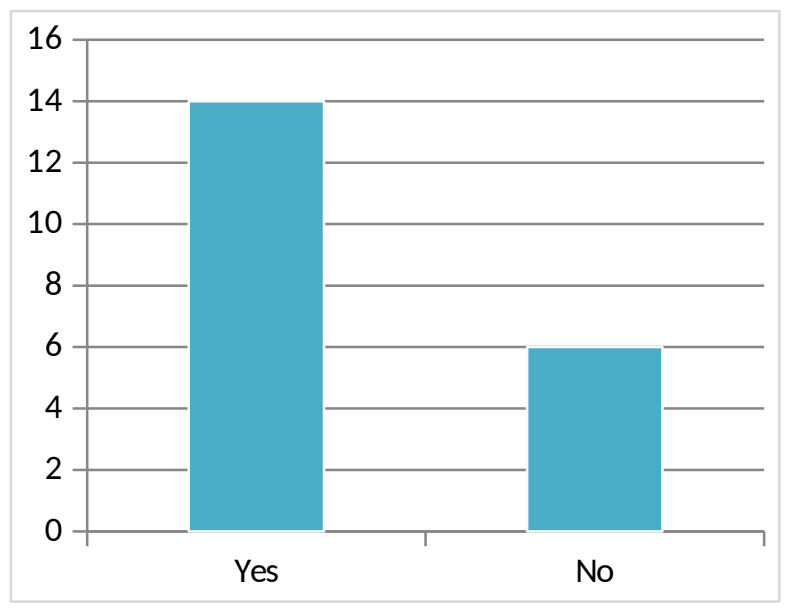

Fig. 9: Used computer \& internet in making lessons in last 2 months

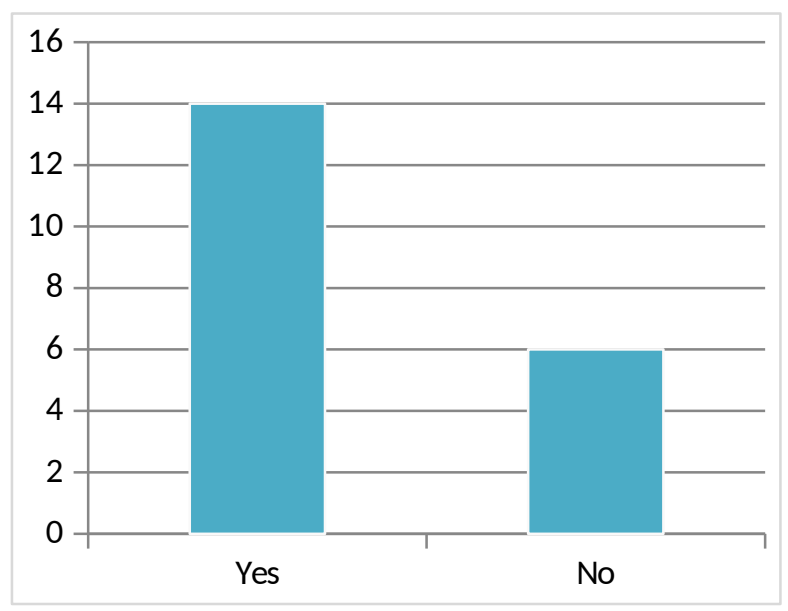

Fig. 10: Used computer and internet for teaching in front of class in last 2 months

There is no second opinion on the fact that there is a shortage of teachers in schools. There are schools that have 3-4 teaching staff on 2-3 classes for on average 120 
students in total strength. There are no dedicated teachers for each subject and hence a single teacher is responsible for more than 3 or 4 subjects to teach. That means the teacher who is not so proficient and comfortable with the subject is forced to teach that too owing to a lack of teachers. To overcome this limitation and to deliver the lecture efficiently, teachers use ICT tools such as the internet either on mobile phones or computers to gather knowledge about other subjects' topics to prepare their instructions. Here one thing to be noted that, for this purpose, teachers use their personal equipment because schools do not have the infrastructure for ICT adequately.

\section{2) Ability}

The views of the teachers on the future availability of training programs and their present knowledge and skills are clearly divided. But largely the respondents agreed on the view that the younger the person is, the better the knowledge and skills s/he has in the context of operating ICT and technical tools. Few of the respondents who belong to the older generation admitted the viewpoint that the generation which they belong to has problems with handling technology and hence would struggle in adopting technology during teaching.

A teacher on average has a lecture of 35 to 45 minutes for over strength of 40-45 students each class. Teachers have to teach more than a single subject and generally, it is the routine that the teacher gives classes for 3 to 4 subjects in a day to either a single or many classes depending on the timetable. It would be easy for teachers if they would have better access to ICT tools to prepare instructions and study materials, it would have saved their time and quality education could also be ensured which ultimately would benefit the students.

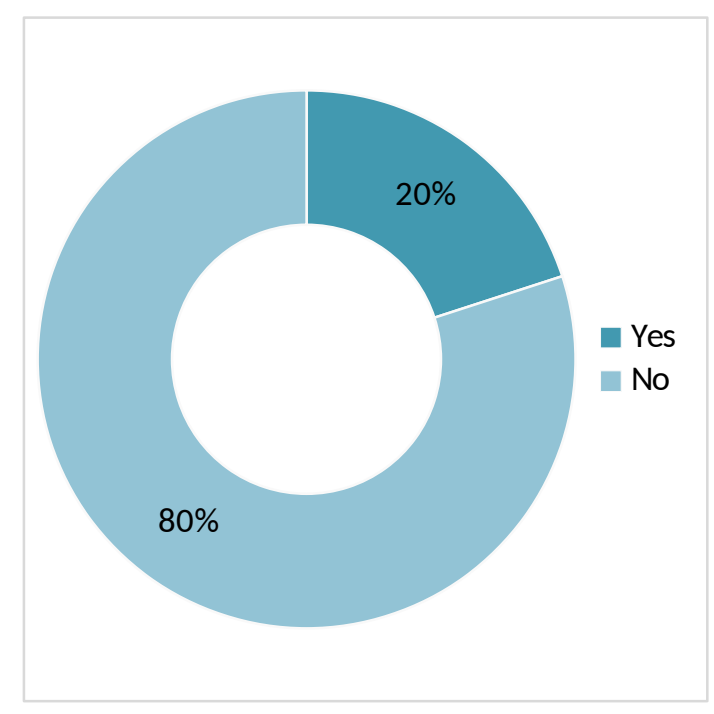

Fig. 11: Undergo professional training for ICT

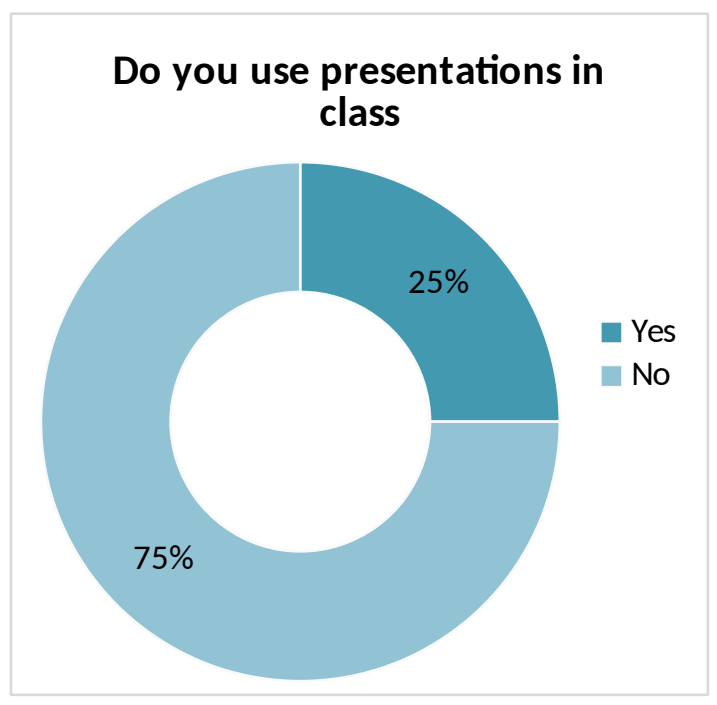

Fig. 12: Do you use presentations in class?

It is clearly evident from the responses that the maximum of the teachers didn't receive any professional training for ICT integrated teaching methods. However, training programs are running in the state in collaboration with private firms yet their reach remains limited. This has a clear effect on the second question which is asked to them, "Do you use presentations in class for teaching?" Maximum of the respondents said no in their answer that they don't use presentations and has two foremost reasons for it, first is the availability and accessibility issue in the context of ICT tools and technics and second is the lack of skills as they did not receive any professional training related to it.

When it comes to the technology handling skills there is an evident age-based divide among teachers. Those who belong to the old age category are struggling with it and those who are young have more proficiency when compared.

\section{3) Attitude}

There is no doubt in saying that limited access to ICT and unequal skills which teachers acquire have been responsible for the slow adaptation of ICT at the school level. But one more factor which is responsible for the degree of using ICT is the attitude, whether it's of students or teachers. According to the responses received while interviewing teachers and also from the literature read and analyzed earlier before this study, most of the teachers have a positive attitude towards ICT and highly optimistic about introducing technology in education. There were views of the teachers who said, not only to the students but teachers would also be benefitted from the introduction of ICT aided education.

However, there are responses from the teachers in which they said that introducing technology to education is unnecessary and would be an obstacle in teaching and 
hailed conventional ways and methods of teaching. This is the plain reluctance and aversion with the use of technology that they have. This negative perception about ICT and its introduction to education could be due to a lack of awareness or due to the inability to adapt ICT. This unawareness and lack of knowledge related to the benefits of ICT integrated education among a few teachers is due to lack of training and education.

\section{DISCUSSION}

Thanks to the digital revolution that the world is drifting towards an "information society" from being an "industrial society" in the last two decades. Digital technologies, specifically ICT are having and leaving a significant impact on our lives. By saying this, it doesn't mean that ICT and digital changes have altogether only positive impacts on the lives of people. ICT may cause significant good or harm depending on the design, execution, and implementation of it. Many elite private schools are experimenting with ICT integration in education from smart classrooms or e-classrooms to providing laptops, computer labs, and tablets. The central government of India and other states' government has tried to integrate education with ICT through various schemes and programs because the argument is largely accepted that "ICT has the potential to improve the quality and status of education".

To integrate education with ICT could have many aims but these two largely; ameliorating the present status and quality of education with the help of improving the process of teaching and learning and for the development of processes of education for improved management and administration. Notwithstanding, the measures espoused to accomplish these goals have been discrepant and inadequate.

\section{A. ICT and Infrastructure}

The study revealed how the state-run government schools are lacking basic infrastructure when it comes to ICT, despite the fact that the state had adopted the ICT policy more than a decade back. The computer or ICT labs should be seen as a very basic part of school infrastructure now, and then only the opportunities could be provided to teachers and students to integrate education with ICT at their level. The initial investments needed to set up an ICT lab in a school includes civil or construction, electrical, and furniture costs. Dependable power supply methods like solar energy could be the gamechanging criteria for the success of this program. However, like the Kerala model, the local communities could be asked to provide and contribute to this component.

This inadequate infrastructure is very much dependent on the factor 'Resource Allocation' by the government of Uttarakhand. In a close-talk with a district-level official, it was informed that in Haridwar district, since 2014, no budget has been disbursed for the ICT section under the whole education budget of the state. However, provisions for the budget were made every year, but due to a lack of clarifications on guidelines, it lapsed year after year. The last budget for ICT integration in higher secondary and senior secondary schools which was disbursed was around 45 lakhs in total including the establishment of labs, purchasing of machines, etc. It is to be noted that the Haridwar district has six blocks in total comprising of more than 50 secondary and senior secondary schools. If we look at the budget allocation then, on average it is less than 1 lakh per school which is highly inadequate. The condition would have improved if the budget for ICT in the past few years did not collapse and if that continues then it would be very hard to bridge the digital divide between the student of private schools and government-run schools.

\section{B. ICT and Teachers}

NCERT also prepared the national level ICT curriculum, which includes a program for Teachers Professional Development (TPD). This program has workshops for teachers where they have face to face interactions with developers. This document of NCERT regarding ICT needs to be contextualized by the state government of Uttarakhand for successfully implementing ICT in schools.

The multi-functionality forced upon the teachers, usually overburdening the teachers which are adversely affecting their performance. Schools are running short of teachers and hence available teachers are asked to teach many subjects to different classes. The teacher has proficiency in his/her subject but asked to teach the subjects which are completely out of their domain and this negatively impacts their capacity to deliver meaningful instructions. During elections or any other government function, teachers' duty was changed from being a teacher to a government official who is doing work other than teaching. These issues need to be addressed immediately to prevent further rupture to the education process in schools.

\section{ICT and Curriculum}

One of the major drawbacks of ICT policy for the education of the state of Uttarakhand is that computer education is not included in a core syllabus and left as a choice based on the voluntarily selected subject. Ironically, it was asked to every school to adopt ICT policy but the curriculum for computer science as a separate subject was not developed and this situation remains the same till now. The level of computer literacy among students came out to be very low and those who have acquired some information about it are very basic and theoretical. This is understood as the schools are lacking ICT infrastructure, the practical exposure to the machine is certainly limited and so their practical knowledge about computers. 
How ineffective the course curriculum for computer education is can be proved by comparing the textbooks of private schools and government schools. For example, when the computer sciences' textbooks for the tenth class of private school and state government-run schools were compared, then it shows that in private schools, students were taught HTML programming language whereas, in state-run government schools, students were still taught basics.

There is a lack of dedicated teaching staff for computer education. Few schools that have computer labs have hired an outside faculty to operate computer lab and teach basics to the students every if they come to the labs. However it is not done regularly because owing to irregular payment, outsourced faculties leave the school frequently.

We have to accept the fact that largely those families who cannot afford private education owing to limited resources of income send their children to government-run schools. These families are those who belong to socially and economically backward and deprived sections of the society. Governments aforementioned many times that they are aiming to ensure education for all, and hence their responsibilities lie on the government to provide them not only the education but the quality education so that their status in the society could be improved and could live a dignified life.

\section{CONCLUSION \& Future SCOPE}

In India, on the role of technology in education and its use in the teaching and learning process in classrooms, very limited research is done until now. The inadequate knowledge and awareness about ICT are responsible for selecting inappropriate components and adopting irrelevant models that provide sub-optimal outcomes. One more risk is there i.e., vendor-sponsored research in this area which might distort the research. There is a need for comprehensive and rigorous research work and documentation, ranging from the ICT integrated education program design to implementation processes and results, to find out the pros and cons of the process adopted, to analyze the outcomes, and to provide a cornerstone for maturing and refining the model.

There are four main and important components identified for the successful implementation of ICT in schools.

1. Foremost is to ensure adequate infrastructure in the schools, including basic infrastructure to the devices and connectivity. There should be effective provisions that need to be made by the government. This infrastructure should be supportive of student-teacher learning and teaching as well as the administration of school education.

2. To get desired outcomes from the program, it is imperative that teachers should be equipped with required training and traits so that a smooth transition from traditional ways of teaching to tech- nological advancements could occur. There should be teachers' professional development training provisioned in the whole program.

3. There is a need to create an open education platform for students and for teachers too, where pooling of information and ideas could take place. This would help in developing an effective curriculum which would be in result more compatible with the moving world. This would promote community learning practices and would ensure the model of "learning from doing" is followed up well.

4. There is a need to create state-level ICT integration infrastructure so that it can be followed and implemented uniformly.

This study is conducted in Roorkee Block which is a completely accessible and urbanized city of the state. This place has no geographic challenges and people here enjoy certainly better living standards when compared to the rest parts of the state which has geographic challenges as it is a hilly state. The condition is worrying in Roorkee itself, and hence it is not so difficult to guess the situation of ICT integration in schools in other parts of the state.

The piecemeal nature of the above-mentioned efforts has been the reason for the failure of the ICT program most of the time. The decision-making process is so delayed that in the last few years budget collapsed because the department was not provided with the essential guidelines. This delayed functionality of the government shows how the government is ignorant of this policy. However, the government is spending a lot of money on other programs like RMSA and Girls students' residential schools' development to increase the enrollment rate and to reduce the dropout rate among girl students. The facilities related to the sanitation got the boost under the Swacch Bharat mission, as many toilets were constructed, girl students were provided with extra care and facilities, the element of computer education and ICT integration is completely ignored.

Now the government is asking the schools to look for help from the corporates under their CSR. This means that the government wants the school administration to establish contacts with corporate firms so that they can contribute to maintaining the ICT infrastructure in the schools. However success rate to this idea is very little because only one or two corporate firms contributed to this, that too not so significant. The local NGOs and clubs like the Rotary club are trying to address shortcomings in these government schools by providing stationery, mid-day meals, and uniforms to the students but when it comes to contributing towards ICT establishment, none took the initiative as of now. The simple reason is that it requires a lot of investment which a small NGO or a collective of people cannot afford to do. Let us assume, if in some places this idea of the government worked well, then what 
about the rest of the places? Hence government should not be in a position of rollback when they are held accountable constitutionally to provide just education for all and to be specific for those who belong to socially and economically backward sections of the society. ICT could be a significant step that can eliminate the barriers related to the region, gender, caste by facilitating a higher degree of permeability of education.

\section{Let us first MAKE INDIA then MAKE IN INDIA.}

\section{A. Future Scope}

Future researchers may workout to design any working module founded on a theoretical framework that can be utilized by the government of the state.

There is a very recent trend which is developing nations are witnessing and so is India, which is using mobile-based applications. This is possible that in a few years the m-service could become very popular. Future work could be done to study or implement the newly introduced m-services integrated with the internet in the sector of education.

India is the home to the second-largest population in the world and hence resource scarcity is already an economic and political issue in India. There is a need for further research to find out creative solutions where technology and education can be integrated and shared.

\section{REFERENCES}

[1] Wighting, M. J. (2006). Effects of computer use on high school students' sense of community. The Journal of Educational Research, 99(6), 371-380.

[2] Kafai, Y. B., \& Sutton, S. (1999). Elementary school students' computer and internet use at home: Current trends and issues. Journal of Educational Computing Research, 21(3), 345-362.

[3] Valentine, G., Holloway, S., \& Bingham, N. (2002). The digital generation?: Children, ICT and the everyday nature of social exclusion. Antipode, 34(2), 296-315.

[4] Hassana, R. A. (2007). ICT as a Learning Tool to assist Teaching ICT in Primary Schools. Coventry University, School of Art and Design, UK.
[5] Serinshaw P. (2004). British educational communications and technology agency (BECTA). UK.

[6] Kennewell, S. (2013). Meeting the standards in using ICT for secondary teaching: A guide to the ITTNC. Routledge.

[7] Gupta, S., Garg, S., Dixit, J. (2011). Use of technology in education: a paradigm shift form little media to $\mathrm{m}$ learning. University news. Vol. 49. No 2. Pp 1-8.

[8] Vijay K. R. (2011). Technology: a catalyst of teaching learning process. Edutrack. Vol. 1. No.11. pp 1-5.

[9] Praveena, K. B., \& Srinivasa, K. S. (2011). Interactive multimedia: A technological wave in education.

[10] Anandan K. \& Gopal B. V. (2011). Information and communication technology in classroom instruction. Edutrack. Vol.11. No. 1. Pp 1-10

[11] Sasmita K. (2011). ICT in classroom instruction. Edutrack. Vol 1, No. 1. Pp 69-99.

[12] Jaiswal, D. (2011). Role of ICT in Teacher Education. Edutracks, 10(11), 9-10.

[13] Suwanna R. (2004). Effectiveness of computer assisted instruction for primary school students: an experimental study. Ph.D. thesis. South Gujarat University. Surat.

[14] Bhatt, A. Y. (2010). Computer assisted instruction in physics for the student of standard XII: an experimental study.

[15] Jain, N. (2002). A study of IGNOU teleconferencing for distance learners.

[16] S. Jayaramam. (2006). A study of the relative effectiveness of computer based multimedia learning packages on performance and behavioral outcomes of students of different age groups. University of Madras.

[17] Permar S. R. (2002). A study of effectiveness of computer science instruction at class viii level in Valsad city, M.Ed. Dissertation. CASE, The M S university of Baroda.

[18] Shivani Agarwal, Anjali Jindal, Pooja Garg, \& Renu Rastogi (2017). "Influence of Quality of Work Life on Trust - Empirical Insights from a SEM Application", The Journal of Indian Culture and Business Management, Vol 15, No. 4, pp. 506-25(ISSN 17530806) (ESCI Indexed, ABDC Listed).

[19] Batra, S. (2003). From School Inspection to School Support: A Case for Transformation of Attitudes, Skills, Knowledge, Experience and Training. Management of school education in India.. 